\title{
Spin-echo nuclear magnetic resonance for tissue characterisation in arrhythmogenic right ventricular cardiomyopathy
}

\author{
L Menghetti, C Basso, A Nava, A Angelini, G Thiene
}

\begin{abstract}
Objective-Arrhythmogenic right ventricular cardiomyopathy (ARVC) is a myocardial disorder characterised clinically by ventricular arrhythmias that can cause cardiac arrest and morphologically by fatty or fibro-fatty myocardial atrophy of the right ventricle. In vivo tissue characterisation without endomyocardial biopsy would be useful. The aim of this study was to investigate the diagnostic accuracy of spin-echo nuclear magnetic resonance (NMR) for tissue characterisation in ARVC.

Patients and methods-Twenty three subjects (15 men and eight women, aged 18-49, mean 34) were studied with spinecho T1-weighted NMR and multislice scan. Fifteen had a clinical diagnosis of ARVC and eight were controls (age and sex matched subjects). Data were independently evaluated by two expert observers.

Results-In the control group NMR was always negative (100\% specificity). Ten of the 15 patients with ARVC had an abnormal NMR result (67\% sensitivity), with areas that had a signal intensity close to that of pericardial or subcutaneous fat. In the remaining five cases the NMR signal was inadequate. Nine patients underwent both NMR and endomyocardial biopsy; biopsy was positive in eight (89\%) and NMR was positive in five (56\%).

Conclusions-NMR is a useful non-invasive diagnostic tool in the evaluation of fatty replacement in ARVC. The technique can be used with other procedures in the initial diagnostic evaluation and is a useful alternative tool in the long term follow up of patients with ARVC.
\end{abstract}

(Heart 1996;76:467-470)

Keywords: arrhythmogenic right ventricular cardiomyopathy; nuclear magnetic resonance; endomyocardial biopsy

Arrhythmogenic right ventricular cardiomyopathy (ARVC) is a heart muscle disease of unknown aetiology, characterised pathologically by segmental or diffuse fibro-fatty or fatty replacement of the right ventricular myocardium and clinically by ventricular arrhythmias which can lead to cardiac arrest. $^{1-6}$ The disease is often familial with autosomal dominant inheritance and variable penetrance ${ }^{78}$; gene defects have been mapped to chromosomes 14 and $1 . .^{10}$ Those affected are young apparently healthy people, frequently engaged in sports, and with a normal heart at a routine investigation. Patients may complain of syncope and/or palpitations related to ventricular arrhythmias, usually of left bundle branch block morphology. Sometimes ARVC presents as sudden death, often during strenous exercise. ${ }^{34}$ In vivo diagnosis is based on clinical demonstration of structural, functional, and electrophysiological abnormalities attributable to the underlying histological changes. ${ }^{11}$ Nuclear magnetic resonance (NMR) is a non-invasive tool with an optimal spatial resolution, able to distinguish by means of spin-echo $\mathrm{T} 1$-weighted pulse sequences between normal myocardium and fatty or fibrous tissue. ${ }^{12} \mathrm{We}$ assessed the diagnostic accuracy of spin-echo NMR as potential tool for in vivo tissue characterisation of fibro-fatty and fatty replacement of the right ventricular myocardium.

\section{Patients and methods}

We studied 15 patients with ARVC (10 men, five women; aged 18-49, mean 35.5 ) and eight age and sex matched control subjects (five men, three women; aged 18-46, mean $31 \cdot 2)$.

The diagnosis of ARVC was based on major and minor diagnostic criteria of the Task Force of Working Group on Myocardial and Pericardial Disease of the Scientific Council on Cardiomyopathies of the International Society and Federation of Cardiology. ${ }^{11}$

Ten $(66 \%)$ subjects had a family history of ARVC and/or sudden death. All 15 had echocardiographic and/or angiographic evidence of global and/or regional dysfunction and structural alterations; inverted $T$ waves in right precordial leads were detected in three $(20 \%)$, left bundle branch block type ventricular arrhythmias in $10(66 \%)$, and positive late potentials on signal averaged ECG in 13 (85\%). Endomyocardial biopsy was performed in nine patients. It showed fibro-fatty replacement of the right ventricular myocardium in eight (89\%), which was diagnostic of ARVC.

NMR was performed by means of a Philips device T5 $(0.5$ tesla). A electrocardiographically gated spin-echo T1-weighted multislice scan was used (TE $=30 \mathrm{~ms}$, slice thickness 
Table 1 Spin-echo NMR images and endomyocardial biopsy findings in 15 patients

\begin{tabular}{|c|c|c|c|c|c|c|c|}
\hline \multirow[b]{2}{*}{ Sex, age } & \multicolumn{4}{|c|}{ Right ventricle } & \multirow[b]{2}{*}{$\begin{array}{l}\text { Left } \\
\text { ventricle }\end{array}$} & \multirow{2}{*}{$\begin{array}{l}\text { Interven- } \\
\text { tricular } \\
\text { septum }\end{array}$} & \multirow{2}{*}{$\begin{array}{l}\text { Endomyo- } \\
\text { cardial } \\
\text { biopsy }\end{array}$} \\
\hline & $\begin{array}{l}\text { Antero- } \\
\text { lateral }\end{array}$ & Inferior & Apex & Outflow & & & \\
\hline $\begin{array}{l}\text { M, 43 } \\
M, 27 \\
M, 29 \\
M, 24 \\
F, 40 \\
M, 21 \\
F, 22 \\
M, 49 \\
F, 49 \\
M, 38 \\
M, 34 \\
M, 24 \\
F, 41 \\
M, 34 \\
F, 49\end{array}$ & $\begin{array}{l}\text { I } \\
\text { I } \\
\text { I } \\
\text { I } \\
\text { I } \\
\text { H } \\
\text { H } \\
\text { H } \\
\text { H } \\
\text { H } \\
\text { H } \\
\text { H } \\
\text { H } \\
\text { H } \\
\text { H }\end{array}$ & $\begin{array}{l}\mathbf{N} \\
\mathbf{N} \\
\mathbf{N} \\
\mathbf{N} \\
\mathbf{I} \\
\mathrm{H} \\
\mathrm{H} \\
\mathrm{H} \\
\mathrm{I} \\
\mathrm{H} \\
\mathbf{I} \\
\mathbf{I} \\
\mathbf{N} \\
\mathrm{H} \\
\mathrm{H}\end{array}$ & $\begin{array}{l}\text { I } \\
\mathbf{N} \\
\mathbf{N} \\
\mathbf{N} \\
\mathbf{I} \\
\mathbf{H} \\
\mathbf{H} \\
\mathbf{H} \\
\mathbf{N} \\
\mathbf{H} \\
\mathrm{H} \\
\mathbf{H} \\
\mathbf{N} \\
\mathbf{N} \\
\mathbf{H}\end{array}$ & $\begin{array}{l}\mathbf{N} \\
\mathbf{I} \\
\mathbf{N} \\
\mathbf{N} \\
\mathbf{I} \\
\mathbf{H} \\
\mathbf{H} \\
\mathbf{H} \\
\mathbf{H} \\
\mathbf{H} \\
\mathbf{H} \\
\mathbf{I} \\
\mathbf{N} \\
\mathbf{N} \\
\mathbf{H}\end{array}$ & $\begin{array}{l}\mathbf{N} \\
\mathbf{N} \\
\mathbf{N} \\
\mathbf{N} \\
\mathbf{N} \\
\mathbf{N} \\
\mathbf{N} \\
\mathbf{N} \\
\mathbf{N} \\
\mathbf{N} \\
\mathbf{N} \\
\mathbf{N} \\
\mathbf{N} \\
\mathbf{N} \\
\mathbf{H}\end{array}$ & $\begin{array}{l}\mathbf{N} \\
\mathbf{N} \\
\mathbf{N} \\
\mathbf{N} \\
\mathbf{N} \\
\mathbf{N} \\
\mathbf{N} \\
\mathbf{N} \\
\mathbf{N} \\
\mathbf{N} \\
\mathbf{N} \\
\mathbf{N} \\
\mathbf{N} \\
\mathbf{N} \\
\mathbf{N}\end{array}$ & $\begin{array}{l}\text { Fibrosis } \\
\text { Negative } \\
\text { NP } \\
\text { Fibrosis } \\
\text { Fibrosis } \\
\text { Fibrosis } \\
\text { Fibro-fatty } \\
\text { NP } \\
\text { Fibro-fatty } \\
\text { NP } \\
\text { Fibrosis } \\
\text { NP } \\
\text { NP } \\
\text { NP } \\
\text { Fibro-fatty }\end{array}$ \\
\hline
\end{tabular}

$\mathrm{H}$, high intensity; I, inadequate; $\mathrm{N}$, normal; NP, not performed.

$9 \mathrm{~mm}$, interslice gap $1 \mathrm{~mm}$ ). Images of the heart were obtained in transverse and sagittal planes.

Two observers blindly and independently evaluated all $\mathrm{T} 1$-weighted spin-echo images. Signal intensity was evaluated at four sites in the right ventricle (inferior, apex, outflow, anterolateral) and at the level of interventricular septum and left ventricular free wall. Spinecho NMR was regarded as abnormal when there was a high intensity, bright signal caused by fatty tissue and a low intensity, dark signal caused by fibrous tissue instead of normal myocardium. ${ }^{12}$ Furthemore, the signal was regarded as inadequate if it was impossible to distinguish between hyperintense areas and artifacts.

Finally, cardiac chamber dimensions and morphology as well as wall thickness were evaluated.

\section{Results}

Spin-echo NMR was negative in all the control group: no anatomical site was considered to be abnormal in terms of signal intensity or morphology ( $100 \%$ specificity) and a hyperin-

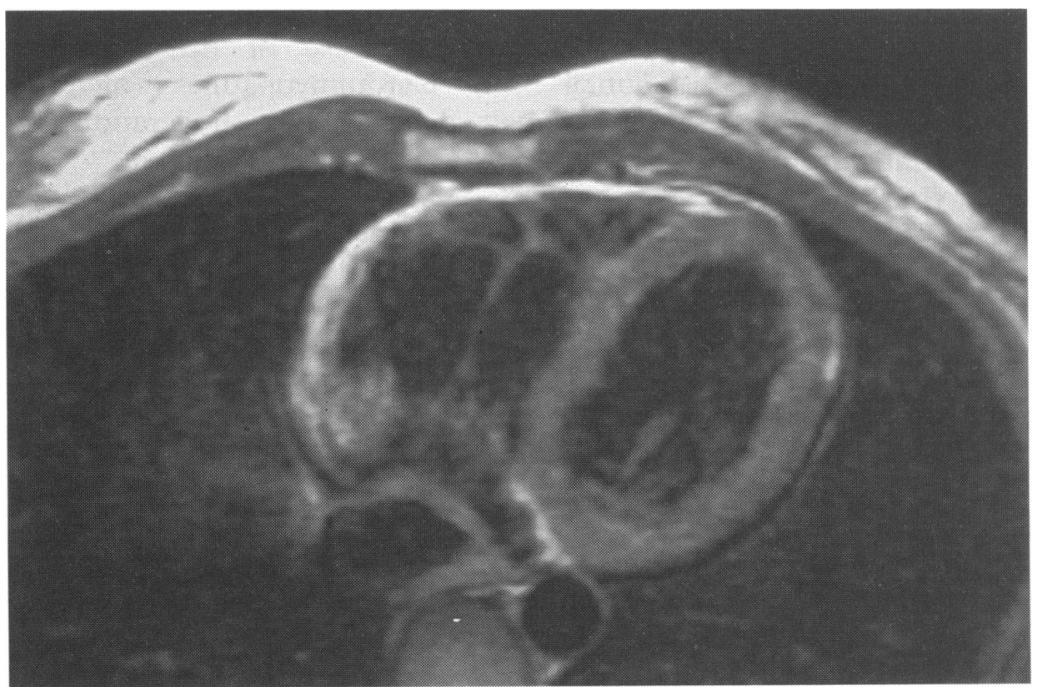

Figure 1 A 22 year old woman with history of dizziness and sustained ventricular tachycardia with left bundle branch block morphology. Short axis nuclear magnetic resonance shows a mildly dilated right ventricle with a brighter signal from a thin anterior free wall. tense signal was detected only at the level of atrioventricular sulcus which is usually rich in adipose tissue.

Table 1 summarises the results in the 15 patients with clinical diagnosis of ARVC.

An abnormally hyperintense bright signal was detected in 10 out of 15 (sensitivity $67 \%$ ) patients. In the remaining five, the NMR signal was considered to be inadequate and not informative.

The anterolateral free wall of the right ventricle was affected in all NMR positive patients, the inferior wall in six, the apex in seven, and the outflow tract in seven (fig 1). Five patients showed a diffuse involvement of the right ventricle (free wall, inferior, apex, outflow tract), with a significant enlargement of the right ventricular chamber. Furthermore, the right ventricular wall was thin in three and there was an irregular endocardial outline in two.

NMR was always normal at the level of interventricular septum and only one patient had involvement of the left ventricular free wall, showing both a hyperintense signal and cavity enlargement. Evaluating the NMR signal intensity at the level of anterolateral right ventricular free wall was particularly difficult.

We never saw the clear low intensity dark signal that indicates fibrous tissue replacement.

Nine patients, with a diagnosis of ARVC, had both NMR and endomyocardial biopsy (table 2). In eight (89\%) endomyocardial biopsy confirmed ARVC, caused by fibrofatty replacement in three and isolated fibrous replacement in five (fig 2). Spin-echo NMR was positive in five (56\%) and equivocal in four because of an inadequate signal. Among these four endomyocardial biopsy was positive in three with isolated fibrous replacement and negative in one.

Table 2 Comparison of endomyocardial biopsy and NMR results in nine clinically affected patients

\begin{tabular}{lll}
\hline Result & Endomyocardial biopsy & NMR \\
\hline Positive & $8(89 \%)$ & $5(56 \%)$ \\
Negative or doubtful & $1(11 \%)$ & $4(44 \%)$ \\
Total & 9 & 9 \\
\hline
\end{tabular}




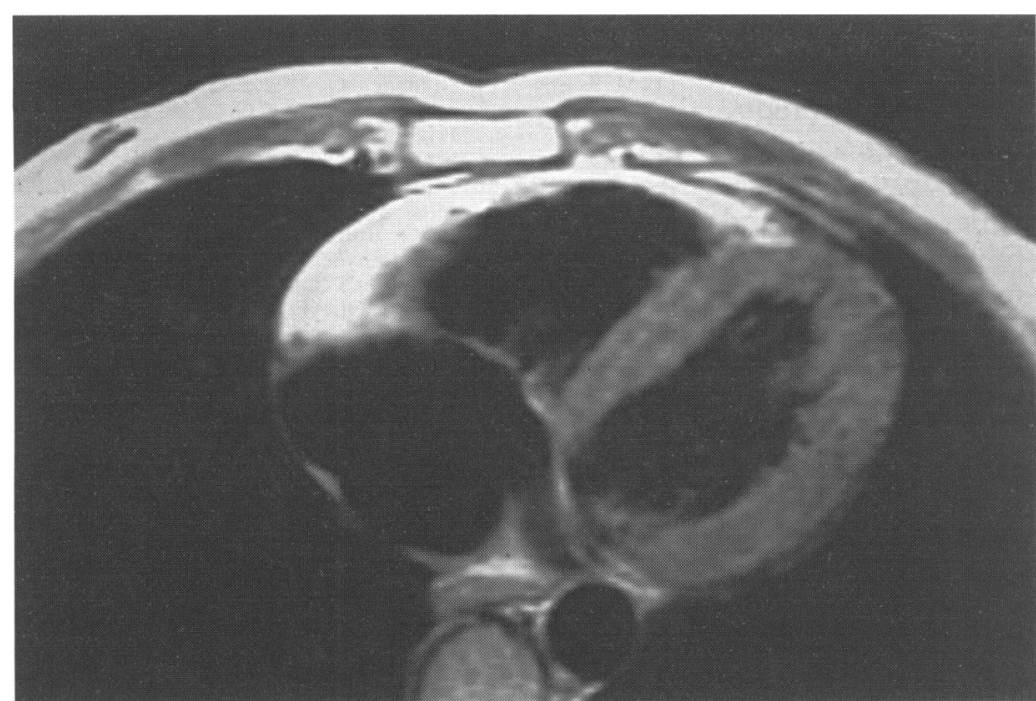

$\boldsymbol{A}$

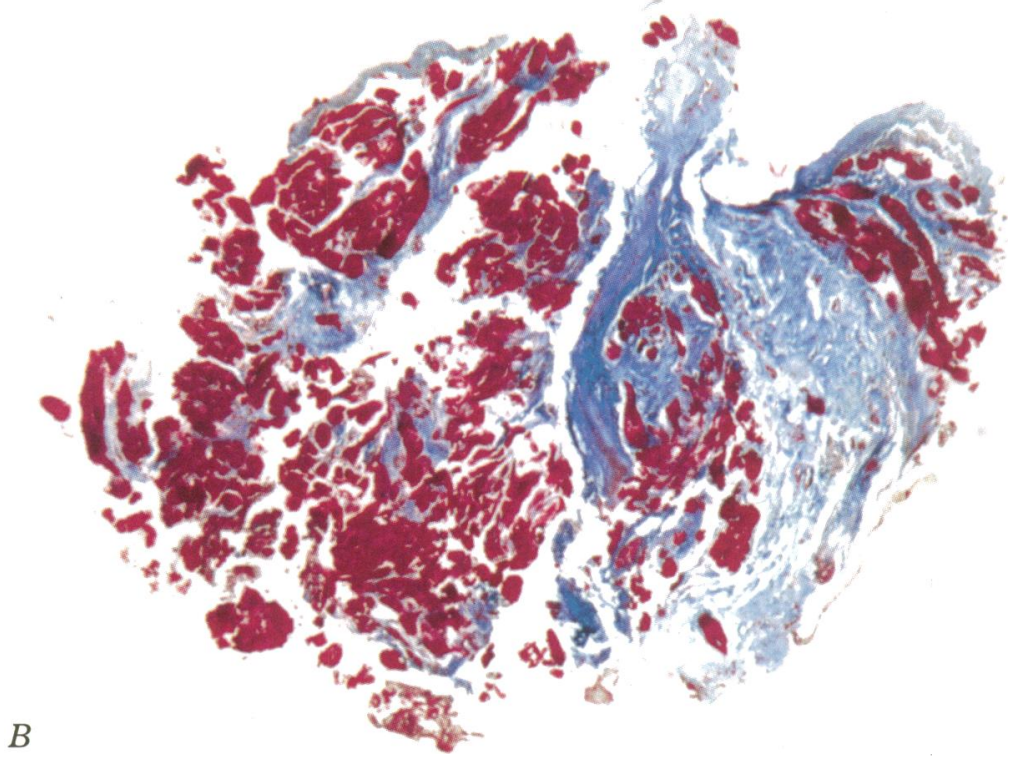

Figure 2 A 21 year old man with family history of ARVC and spontaneous sustained ventricular tachycardia with left bundle branch block morphology. Short axis nuclear magnetic resonance shows a diffuse bright signal from the right ventricular wall, suggestive of extensive myocardial fatty replacement $(A)$. Endomyocardial biopsy shows extensive replacement of the myocardium by fibrosis (azan-Mallory stain, original magnification $\times 45)(B)$. image by echocardiography or angiography. ${ }^{21-25}$ Moreover, NMR is a non-invasive technique that does not need contrast medium and gives an excellent contrast between blood, myocardium, and soft tissues, with the opportunity to characterise specific tissues by estimating magnetic relaxation times. ${ }^{12}$ Fatty replacement is characterised by an increased signal intensity, close to that of pericardial or subcutaneous fat on T1-weighted spin-echo images, whereas fibrous tissue gives decreased signal intensity compared with normal myocardium.

Our study indicates that spin-echo NMR has a $100 \%$ specificity for the diagnosis of ARVC, which is higher than for other techniques. However, sensitivity seems lower, with an abnormal, high intensity signal caused by fatty replacement found in only $67 \%$ of affected patients.

Previous studies report variable degrees of right ventricular involvement in ARVC on spin-echo NMR. Molinari et al found increases in signal intensity within the myocardial wall of the right ventricle, suggesting fatty replacement, in all the cases, with at least two abnormal areas in the right ventricle ${ }^{20}$ and Ricci et al found them in $53 \%$ of patients. ${ }^{19}$ Even lower sensitivity (22\%) in detecting fatty tissue was reported by Aufferman et al. ${ }^{18} \mathrm{We}$ ascribe these different results to the selection of patients, which included not only those with overt forms of the disease with extensive structural alterations, global functional deterioration, and inducible arrhythmias, but also those with concealed forms without global dysfunction and without inducible arrhythmias.

In our experience, NMR findings were inadequate in $33 \%$ of affected patients. The poor quality of cardiac gated images may be caused by technical problems, patient motion, or cardiac arrhythmias during image acquisition. ${ }^{12}$ The evaluation of the signal in very thin walls may be difficult as well, because it is difficult to distinguish between artifacts and adjacent blood. Moreover, some areas-such as the subtricuspid region-are not always easily distinguished from the atrioventricular sulcus, which is rich in fat.

When we compared the diagnostic accuracy of endomyocardial biopsy and NMR in patients who underwent to both procedures, we found that endomyocardial biopsy was more sensitive ( $89 \% v 56 \%$, respectively). In ARVC patients with inadequate NMR findings, endomyocardial biopsy was negative in one and diagnostic because of isolated fibrous replacement in the remaining three. In neither our study nor in previous report was an abnormal low intensity NMR signal that is consistent with fibrous tissue replacement ever seen, despite histological evidence of fibrosis. Therefore, fibrosis does not seem to be detectable on NMR and the only manifestation may be an extreme thinning of the cardiac wall. Furthemore, the potential sampling error associated with biopsy of a subendocardial site may explain inconsistencies between histological findings and the NMR signal, which is generated by the entire wall thickness. 
In conclusion, spin-echo NMR is a useful non-invasive diagnostic tool in the evaluation of fatty replacement in ARVC. The technique can support echocardiography, angiocardiography, and endomyocardial biopsy investigations in the initial diagnostic evaluation and may be an alternative to other invasive procedures in the long-term follow up of ARVC patients.

This study was supported by Research Project AGING, This study was supported by Research Project AGING, Venice, Italy.

1 Marcus FI, Fontaine GH, Guiraudon G, Frank R, Laurenceau JL, Malergue S, et al. Right ventricular dysplasia. A report of 24 adult cases. Circulation 1982;65: plasia. A

2 Fontaine G, Guiraudon G, Frank R, Tereau Y, Fillette F, Marcus FI, et al. Dysplasie ventriculaire droite arrhythMarcus FI, et al. Dysplasie ventriculaire droite arrhythmogène et malad

3 Thiene G, Nava A, Corrado D, Rossi L, Pennelli N. Right ventricular cardiomyopathy and sudden death in young people. $N$ Engl ₹ Med 1988;318:129-33.

4 Corrado D, Thiene G, Nava A, Rossi L, Pennelli N. Sudden death in young competitive athletes: clinicopathologic correlations in 22 cases. Am F Med 1990;89. 588-96.

5 Thiene G, Nava A, Angelini A, Daliento L, Scognamiglio $\mathrm{R}$, Corrado D. Anatomoclinical aspects of arrhythmogenic right ventricular cardiomyopathy. In: Baroldi $\mathrm{G}$ Camerini F, Goodwin F,eds. Advances in cardiomyopathies. Berlin: Springer-Verlag, 1990;397-408.

6 Basso C, Thiene G, Corrado D, Angelini A, Nava A, Valente M. Arrhythmogenic right ventricular cardiomyopathy: dysplasia, dystrophy or myocarditis ? Circulation opathy: dysplasia,

7 Laurent M, Descaves C, Biron Y, Deplace C, Almange C, Daubert JC. Familial form of arrhythmogenic right ventricular dysplasia. Am Heart $₹$ 1987;113:827-9.

8 Nava A, Thiene G, Canciani B, Scognamiglio R, Daliento L, Buja GF, et al. Familial occurrence of right ventricula dysplasia. A study involving nine families. $\mathcal{F} \mathrm{Am}$ Co Cardiol 1988;12:1222-8.

9 Rampazzo A, Nava A, Danieli GA, Buja GF, Daliento L, Fasoli G, et al. The gene for arrhythmogenic right ventricular cardiomyopathy maps to chromosome $14 \mathrm{q} 23$ q24. Hum Mol Genet 1994;3:959-62.

10 Rampazzo A, Nava A, Erne P, Eberhard M, Vian E, Slomp $P$, et al. A new locus for arrhythmogenic right ventricular cardiomyopathy (ARVD2) maps to chromosome 1q42q43. Hum Mol Genet 1995;4:2151-4.

11 McKenna WJ, Thiene G, Nava A, Fontaliran F, Blomstrom-Lundqvist, Fontaine G, et al. Diagnosis of arrhythmogenic right ventricular dysplasia/ cardiomyopathy. Br Heart $₹$ 1994;71:215-8.

12 Ehman RL, Julsrud PR. Magnetic resonance imaging of the heart: current status. Mayo Clin Proc 1989;64:1134-46.

13 Angelini A, Thiene G, Boffa GM, Calliari I, Daliento I Vlente $M$, et al. Endomyocardial biopsy in right ventricular cardiomyopathy. Int $₹$ Cardiol 1993;40:273-82.

14 Hamada S, Takamiya $M$, Ohe T, Ueda $H$. Arrhythmogenic ramada S, Takamiya M, Ohe T, Ueda H. Arrhythmogenic right ventricular dysplasia: evaluation

15 Klersy C, Raisaro A, Salerno JA, Montemartini C, Campani R. Arrhythmogenic right and left ventricula disease: evaluation by computed tomography and nuclear magnetic resonance imaging. Eur Heart $\mathcal{f} 1989 ; 10$ (suppl D):33-6

16 Wolf JE, Rose-Pittet L, Page E, Borrel E, Bertrand B, Lebas JF, et al. Mise on evidence par l'IRM des lesion parietales au cours des dysplasies arythmogenes du ventricule droit. Arch Mal Coeur 1989;82:1711-7.

17 Blake LM, Scheinman MM, Higgins CB. MR features of arrhythmogenic right ventricular dysplasia. Am $\mathcal{f}$ Radiol 1994;162:809-12.

18 Auffermann W, Wichter T, Breithardt G, Joachimsen $\mathrm{K}$ Peters PE. Arrhythmogenic right ventricular disease: MR Peters PE. Arrhythmogenic right ventricular disease: MR imaging

19 Ricci C, Longo R, Pagnan L, Dalla Palma L, Pinamonti B, Camerini $\mathrm{F}$, et al. Magnetic resonance imaging in right ventricular dysplasia. Am 7 Cardiol 1992;70:1589-95.

20 Molinari G, Sardanelli F, Gaita F, Ottonello C, Richiardi $\mathrm{E}$, Parodi RC, et al. Right ventricular dysplasia as a generalized cardiomyopathy ? Findings on magnetic resonance imaging. Eur Heart $\mathcal{F} 1995 ; 16: 1619-24$

21 Daubert C, Descaves C, Foulgoc JL, Bourdonnec C, Laurent $M$, Gouffault J. Critical analysis of cineangiographic criteria for diagnosis of arrhythmogenic right ventricular dysplasia. Am Heart F 1988;115:448-59.

22 Daliento $L$ Rizzoli G, Thiene G, Nava A, Rinuncini M, Chioin $R$, et al. Diagnostic accuracy of right ventriculography in arrhythmogenic right ventricular cardiomyopathy. Am $\mathcal{f}$ Cardiol 1990;60:741-5.

23 Blom. Wallentin I, Jonsson R, Olsson SB. Ventricular dimensions and wall motion assessed by echocardiography in patients with motion assessed by echocardiography in patients with 1291-1302.

24 Scognamiglio R, Fasoli G, Nava A, Miraglia G, Thiene G, Dalla Volta $S$. Contribution of cross-sectional echocardiography to the diagnosis of right ventricular dysplasia the asymptomatic stage. Eur Heart $\mathcal{f} 1989 ; 10: 538-42$.

25 Robertson JH, Bardy GH, German LD, Gallagher J Kisslo J. Comparison of two-dimensional echocardiographic and angiographic findings in arrhythmogenic right ventricular dysplasia. Am $f$ Cardiol 1985;55 